\title{
Estado, política educacional e direito à educação no Brasil: "O problema maior é o de estudar"
}

\section{State, educational policy an right to educa- tion in Brazil: "The biggest problem is to study"}

\section{Gilda Cardoso de Araujo ${ }^{1}$}

Trabalhando o sal é amor o suor que me sai

Vou viver cantando o dia tão quente que faz Homem ver criança buscando conchinhas no mar Trabalho o dia inteiro pra vida de gente levar Água vira sal lá na salina Quem diminuiu água do mar Água enfrenta sol lá na salina

Sol que vai queimando até queimar Trabalhando o sal pra ver a mulher se vestir E ao chegar em casa encontrar a família feliz Filho vir da escola problema maior é o de estudar Que é pra não ter meu trabalho e vida de gente levar (Canção do Sal - Milton Nascimento)

\section{RESUMO}

$\mathrm{O}$ artigo trata das relações entre os problemas de acesso, permanência e qualidade e a configuração histórica do Estado brasileiro e, consequentemente, da política educacional que foi traçada a partir dessa configuração. Destaca as profundas desigualdades sociais e regionais e o correlato processo excludente quanto ao direito à educação no Brasil, tanto do ponto de vista normativo-político, quanto do ponto de vista das dinâmicas intraescolares. As conclusões evidenciam a necessidade de reflexão sobre

1 Doutora em Educação pela Universidade de São Paulo (USP), Professora do Programa de Pós-Graduação em Educação da Universidade Federal do Espírito Santo (UFES). E-mail: gilda. vix@terra.com.br 
a dívida histórica do país com a constituição de um sistema nacional de ensino e com a garantia do direito à educação.

Palavras-chave: Estado; política educacional; direito à educação.

\begin{abstract}
The article deals with the relationships between the problems of access, retention and quality and historical configuration of the Brazilian state and therefore the educational policy that was drawn from this setting. Highlights the profound social and regional inequality and exclusionary process correlated to the right to education in Brazil, both in terms of normative and political, as the point of view of the school dynamics. The findings highlight the need for reflection on the historical debt of the country with the establishment of a national education system and ensuring the right to education. Keywords: State; educational policy; right to education.
\end{abstract}

\title{
Introdução
}

Esse artigo trata do "problema maior" que é o de estudar, ou melhor, de ter a possibilidade de acesso, permanência e educação de qualidade para "vida de gente levar" no Brasil, país de dimensões continentais, com profundas desigualdades regionais, de renda, de acesso a bens culturais, entre outras muitas desigualdades típicas do capitalismo.

Entendemos que o "problema maior de estudar" tem profundas ligações com a configuração do Estado brasileiro e, consequentemente, com a política educacional que foi traçada a partir dessa configuração. Enquanto em outros países, já no século XIX, os sistemas nacionais de educação começavam a se articular e a generalização da instrução elementar passava a ser entendida como uma tarefa precípua do Estado nacional, ainda não temos, no Brasil do século XXI, um sistema de educação que possa ser denominado nacional, dadas as profundas disparidades entre redes, sistemas de ensino, entre estados e regiões. Uma amostra dessas disparidades pode ser observada na tabela abaixo: 
TABELA 1 - ENSINO FUNDAMENTAL SEGUNDO REGIÃO ADMINISTRATIVA- 2006

\begin{tabular}{|c|c|c|c|}
\hline Regiões & Matrícula & Abandono & Reprovação \\
\hline Norte & 3.356 .716 & 362.537 & 520.613 \\
Nordeste & 10.887 .853 & 1.284 .458 & 1.797 .919 \\
Sudeste & 12.344 .341 & 399.852 & 1.119 .624 \\
Sul & 4.256 .747 & 103.286 & 575.386 \\
Centro-Oeste & 2.437 .006 & 164.357 & 287.520 \\
Brasil & 33.282 .663 & 2.314 .490 & 4.301 .062 \\
\hline
\end{tabular}

FONTE: MEC/INEP. Censo Escolar 2006

As regiões Sudeste e Nordeste têm a maior concentração de matrículas na etapa obrigatória de escolarização. Entretanto, as regiões mais pobres do país, Norte e Nordeste, apresentam 1.647.000 alunos afastados da escola de ensino fundamental por abandono, de um total de 2.314 .490 , representando $71 \%$ dos alunos brasileiros nessa situação. No que se refere à reprovação, a região Nordeste e Norte, juntas, tiveram 2.318.540 alunos que não foram aprovados, representando $54 \%$ do total de reprovação no País.

Além desses dados, a Pesquisa Nacional de Amostras por Domicílios de 2005 (PNAD, 2005) revela que a taxa de analfabetismo funcional das pessoas de 15 anos ou mais de idade no Brasil é de 23, 3\%, sendo que a divisão regional dessa taxa também é perversa: $22,6 \%$ na Região Norte, $36,3 \%$ na Região Nordeste, $17,5 \%$ na Região Sudeste, $18 \%$ na Região Sul e 21,4\% na Região Centro-Oeste, sendo que a maior concentração do analfabetismo funcional está nos domicílios rurais.

A PNAD 2005 também mostra que, apesar da propalada universalização do ensino fundamental, a média de anos de estudo da população brasileira ainda é muito baixa, o que nos induz a pensar que, se quase todos brasileiros estão entrando na escola há mais de uma década, não conseguem concluir a educação básica (ensino fundamental e médio), conforme a tabela 2. 
TABELA 2- ANALFABETISMO FUNCIONAL DE PESSOAS DE 15 ANOS OU MAIS

\begin{tabular}{c|c}
\hline Regiões & \% \\
\hline Norte & 22,6 \\
Nordeste & 36,3 \\
Sudeste & 17,5 \\
Sul & 18 \\
Centro-Oeste & 21,4 \\
Brasil & $\mathbf{2 3 , 3}$ \\
\hline
\end{tabular}

FONTE: IBGE, PNAD, 2005.

Diante desses dados, pretendemos traçar como se constituíram as políticas públicas de educação no Brasil, analisando seu processo tardio e inacabado, bem como os impactos desse processo na inscrição do direito à educação do ponto vista da racionalidade jurídica e política.

\section{Estado e política educacional no Brasil: trajetória e panorama atual}

O debate sobre a origem da denominação e da instituição Estado é controverso. A utilização do termo "Estado" para designar especificamente a condição de posse permanente e exclusiva de um território e de comando sobre os seus respectivos habitantes é considerada por alguns autores emblema de uma situação nova de rompimento com os ordenamentos políticos precedentes e, por outros autores, é considerada na linha de evolução das instituições precedentes.

Assim, para os autores, como Max Weber (2004), que defendem a ruptura entre a ideia de Estado e os ordenamentos políticos precedentes, seria conveniente falar de "Estado" apenas quando estivesse referido às formações políticas originadas da crise do feudalismo, portanto o Estado teria nascido com a modernidade. Na outra linha, os autores, como Engels (1986), que defendem a continuidade, argumentam que o Estado como ordenamento político de uma comunidade teria surgido na passagem da comunidade primitiva fundada pelos 
laços de parentesco para a comunidade civil.

Se a origem da denominação e da instituição Estado é controversa, a ligação da educação ao Estado é um fenômeno tipicamente moderno, como assinala a historiadora da educação Carlota Boto (1996). Com efeito, até a Revolução Francesa a educação era entendida como aperfeiçoamento individual. Até mesmo o movimento iluminista, que defendia a expansão do esclarecimento como estratégia para o progresso, negava o caráter público da educação, talvez por sua marcada oposição ao Estado Absolutista, o que tornava pouco aceitável a ideia deste Estado assumir a tarefa de instruir as novas gerações. A Revolução Francesa, embora não represente uma ruptura com a tradição da ilustração, significa, do ponto de vista educacional, uma substância nova no debate sobre a institucionalização de um ensino público e universal. A educação, no contexto revolucionário, se conecta a esfera pública e ao civismo, transformando-se em instrumento de regeneração social e, portanto, desvincula-se da dimensão eminentemente individualista de emancipação característica da utopia iluminista.

Dessa forma, de uma perspectiva de dever moral de autoaperfeiçoamento sem referência a um coletivo, a educação passa a ser entendida como um dever moral de aperfeiçoamento social, assumindo a configuração de uma responsabilidade coletiva. Essa passagem é importante porque assinala a ligação entre a ideia de Estado e de educação que servirá de base para a sua compreensão como direito social e para a sua inscrição como um dos componentes da medida de igualdade social.

Contudo, apenas no século XX é que a ideia da educação como propulsora de igualdade econômica e social pode ser relacionada com a de direito a ser garantido pelo Estado. É preciso destacar que a novidade consiste apenas no fato de a educação ser entendida como direito porque, como destacamos, a educação esteve relacionada ao Estado desde a Revolução Francesa e essa tendência foi se consolidando, mesmo no quadro do Estado liberal. Exemplo disso é o livro A riqueza das nações, de Adam Smith (1983), que traduz a aceitação e a defesa do intervencionismo estatal na educação, posto que fosse considerada uma atividade que não podia ser deixada aos particulares, uma vez que não era e nem poderia ser lucrativa. Assim, mesmo na tradição liberal, a educação era considerada uma atividade de interesse geral a ser assegurada pelo Estado.

Com esse breve histórico pretendemos assinalar que as teorias de Estado como referência de análise da educação só ganham materialidade quando a educação passa a ser entendida como direito social que deve ser assegurado por políticas públicas entendidas como o "Estado em ação".

Esse entendimento da relação entre Estado e educação a partir da ideia de formulação de políticas públicas, da ideia do "Estado em ação" começou muito tardiamente no Brasil. A tradição liberal clássica do pensamento político 
brasileiro, representada por autores como Tavares Bastos e Rui Barbosa, nunca foi alheia à ideia de uma limitada intervenção estatal que, sem desconsiderar a ideia de direitos individuais e a extensão das liberdades, pudesse compensar tanto o atraso do país em matéria educacional, quanto à impossibilidade ou falta de vontade política para a criação de escolas.

Todavia, tanto o Império, com a edição do Ato Adicional de 1834, quanto a Primeira República, com o seu federalismo oligárquico, não levaram a frente a ideia de intervenção estatal moderada na área de educação, típica do liberalismo clássico: a educação não era uma tarefa do Estado nacional, mas sim das províncias e, posteriormente, com a Proclamação da República, dos estados.

Assim, enquanto a Europa constituía, no final do século XIX, o seu sistema nacional de educação, o Brasil mitigava essa possibilidade com uma organização de Estado liberal que servia apenas para atender aos interesses políticos e econômicos das elites regionais, adaptando-os a uma estrutura social marcada pelos acordos políticos "pelo alto" e pela concentração de terras, riquezas e saber.

Apenas a partir de 1930 foi criado o Ministério da Educação e Saúde que significou o reconhecimento, no plano institucional, da educação como uma questão nacional. Ato contínuo, o país teve uma série de reformas, medidas e debates de alcance nacional: em 1931 as reformas de Francisco Campos; em 1932, o Manifesto dos Pioneiros da Educação Nova, dirigido ao povo e ao governo no sentido da construção de um sistema nacional de educação; em 1934 a promulgação da Constituição que reconhecia a educação como direito, colocava a exigência de fixação das diretrizes da educação nacional e a elaboração de um plano nacional de educação; durante todo o período de Vargas no poder, a edição das leis orgânicas de ensino.

Essas medidas são correspondentes à configuração de um modelo intervencionista de Estado no país. A crise de 1929, bem como a Grande Depressão que a seguiu, desautorizou o funcionamento pleno do modelo de Estado liberal no Brasil, tornando-se necessária não só a sistemática planificação estatal nos domínios econômicos, como também a incorporação das massas trabalhadoras e das classes médias urbanas ao sistema político.

O objetivo principal desse modelo de Estado não era tanto a redistribuição de renda e de provimento do bem-estar social como foi o caso de muitos países Europeus, mas a transição de uma economia eminentemente agrária para uma industrial. Daí a adoção da concepção de que o Estado seria a grande alavanca do progresso econômico e social do País. Posição que foi reforçada pelas políticas keynesianas aplicadas em diversas partes do mundo a partir de 1930. Para tanto, foi necessária a criação da moderna burocracia - na verdade uma tecnocracia formada por profissionais, civis e militares, engajada em serviço integral, que atuou como o principal agente da transformação econômica do País. 
No período que compreende as décadas de 1930 a 1970 havia duas grandes correntes desenvolvimentistas: a nacionalista e a liberal. Essas duas correntes se fizeram presentes nos embates políticos em torno da polarização que assinalou o longo processo de debate e tramitação da primeira Lei de Diretrizes e Bases da Educação Brasileira. Essa polarização entre o nacionalismo e o liberalismo, na verdade, esteve presente durante todo o período, desde o embate entre católicos e liberais na constituinte de 1933, pelo menos, e assumiu a forma do debate sobre o papel da educação no projeto de desenvolvimento do País.

O regime militar tentou fazer uma síntese dessas duas tendências apelando para um projeto nacional, mas não popular como era propalado nas décadas de 1940 e 1950, acentuando a abertura do País para o capital e os interesses estrangeiros.

Foi apenas a partir do cenário de intermitente inflação das décadas de 197080, da queda do Muro de Berlim, do colapso da União Soviética acompanhada pela descrença na planificação econômica, que esse modelo de Estado começa a ruir no Brasil. O cenário globalizado, hegemonizado pelos Estados Unidos e pelo capitalismo americano, contribuiu para que os princípios da doutrina neoliberal - anti-intervencionistas e privatizantes - predominassem no Brasil, como em outras paragens, afetando as políticas de desenvolvimento até então conhecidas e praticadas.

Esse cenário trouxe um conjunto de representações sociais que enfatizavam o desgaste das instituições políticas (crise de governabilidade) e a inviabilidade de políticas nacionais voltadas para gerir o desenvolvimento econômico e as políticas de renda e de bem-estar social. Bourdieu (1998) numa entrevista publicada no seu livro "Contrafogos" situa as tensões inerentes a essa nova configuração dos Estados nacionais, tensões que de uma maneira figurada seriam entre a mão esquerda do Estado, ou os trabalhadores da área social dos ministérios gastadores (saúde, educação, assistência social), e a mão direita, ou os burocratas dos ministérios das finanças, dos bancos públicos ou privados e dos gabinetes ministeriais. Para Bourdieu (1988) a mão esquerda acha que a mão direita não sabe ou não quer mais saber do que faz a mão esquerda.

Para a educação o impacto dessas transformações é evidente. No livro A era dos extremos o historiador Eric Hobsbawm (1995) afirma que, a partir de 1940, a educação se configurou como uma preocupação mundial que foi progressivamente se tornando central a partir da década de 1940, fundamentalmente pela identificação entre nível superior de escolarização e ascensão social via emprego nas empresas e nos órgãos públicos. Observa-se, então, aquilo que Hobsbawn (1995) denominou como uma verdadeira "revolução social", traduzida num processo significativo de expansão das oportunidades de escolarização da população. 
Assim, o processo de ampliação da educação escolar se deu em estreita correlação tanto com os ideais da sociedade do pleno emprego, quanto da sociedade organizada sob a proteção de um Estado intervencionista do ponto de vista econômico e social.

Com as transformações do capitalismo em escala mundial, esses dois parâmetros são neutralizados e o que se assiste é um atrofiamento do Estado quanto às suas responsabilidades com a educação, que não integra, como vimos, a tradição liberal (daí a propriedade do termo "neo", "novo" liberalismo). Esse atrofiamento do Estado se opõe fortemente ao modelo intervencionista e desenvolvimentista que o País vinha adotando desde 1930, gerando uma nova forma de regulação estatal que se dá não mais pela execução direta, mas pela transferência de encargos, gastos e responsabilidades para outras instâncias administrativas subnacionais, para as escolas e mesmo para as famílias, ao mesmo tempo em que os marcos regulatórios do Estado são redefinidos a partir da lógica típica do mercado de prescrição de metas, objetivos e controle de produtos e resultados.

Exemplo desses novos marcos regulatórios nas políticas educacionais atuais são o Plano de Desenvolvimento da Educação (PDE), a criação de indicadores como o IDEB (Índice de Desenvolvimento da Educação Básica), a expansão (muitas vezes com sobreposição) dos testes padronizados em larga escala com ênfase no rankeamento entre instituições e sistemas de ensino - Sistema de Avaliação da Educação Básica (SAEB), Prova Brasil e Exame Nacional do Ensino Médio (ENEM) ${ }^{2}$ - que desconsideram os processos educativos e valorizam apenas os resultados obtidos.

Dessa forma, desconectam a escola de sua função social, visto que não levam em conta, por exemplo, a capacidade de inclusão que determinada instituição ou sistema de ensino possui. Ora, se a educação é um direito social de cidadania, desconsiderar que escolas ou sistemas que possuem uma necessária (ainda que desacertada) política de inclusão podem apresentar "maus resultados" exatamente por cumprirem o que a sociedade espera do processo de escolarização é uma questão muito séria que pode impactar negativamente nos esforços que vêm sendo realizados para garantir e efetivar o direito à educação de todos os brasileiros, que é o princípio basilar da res publica e da cidadania.

Abordar a relação entre Estado e as políticas educacionais no Brasil constitui grande desafio, visto que nosso liberalismo foi outro, nosso intervencionismo foi outro e, não chegando a consolidar plenamente nem um nem outro, chegamos - por força das alterações no capitalismo mundial - no início do século XXI com a necessidade de diminuir um Estado já diminuto em sua

2 Que se tornou obrigatório no ano de 2009, como critério parcial ou único para ingresso em cursos superiores. 
dívida histórica com a parcela majoritária da população excluída dos requisitos mínimos para uma vida civilizada.

\section{Políticas educacionais e Direito à Educação}

Da forma que modernamente se configurou, o direito à educação pode ser traduzido basicamente em dois aspectos: a oportunidade de acesso e a possibilidade de permanência na escola, mediante educação com nível de qualidade semelhante para todos. $\mathrm{O}$ direito à educação traz uma potencialidade emancipadora do ponto de vista individual e igualitária do ponto de vista social, visto que a sua afirmação parte do pressuposto que a escolarização é niveladora das desigualdades do ponto de partida. Com base nisso, a partir de 1917, a escolarização foi transformada em responsabilidade estatal e social pela maioria dos países mediante inscrição em textos constitucionais (SACRISTÁN, 2000).

Contudo, não se pode confundir a existência de escolas públicas com o direito à educação. $\mathrm{O}$ direito à educação pressupõe o papel ativo e responsável do Estado tanto na formulação de políticas públicas para a sua efetivação, quanto na obrigatoriedade de oferecer ensino com iguais possibilidades para todos. Quando o Estado generaliza a oferta de escolas de ensino fundamental, tem o poder de responsabilizar os indivíduos e/ou seus pais pela frequência.

Portanto, o direito à educação, diferentemente dos demais direitos sociais, está estreitamente vinculado à obrigatoriedade escolar. Isso porque, enquanto os cidadãos podem escolher entre fazer uso ou não dos demais direitos sociais, a educação é obrigatória porque se entende que as crianças não se encontram em condições de negociar se querem ou não recebê-la e de que forma. Paradoxalmente, a educação é ao mesmo um direito e uma obrigação. Assim, o direito de não fazer uso dos serviços educacionais não está colocado como possibilidade e a perspectiva emancipadora não está colocada como ponto de partida e, sim, como ponto de chegada. Daí a relação estreita entre direito à educação e educação obrigatória (HORTA, 1998).

No Brasil o processo de afirmação dos direitos de cidadania (ainda inconcluso) irá conferir um grau maior de ambiguidade nas medidas de proclamação e de implementação do direito à educação, uma vez que apenas a partir de 1988 uma concepção universalista dos direitos sociais foi incorporada ao sistema normativo brasileiro e que o processo de afirmação dos direitos no país foi assinalado pela defasagem entre os princípios igualitários proclamados na lei e a realidade de desigualdade e de exclusão (TELLES, 1999). 
Essa introdução tardia da concepção universalista dos direitos sociais guarda relação com a não institucionalização de uma esfera pública democrática, pois os ideais de igualdade e justiça eram e ainda são introduzidos numa sociedade marcada por relações verticalizadas e autoritárias e, portanto, fraturada internamente por suas contradições.

Além disso, o ideal emancipador e igualitário do direito à educação também foi mitigado pelas próprias relações que se estabeleceram na dinâmica interna da escola, já muitas vezes denunciadas como reprodutoras das desigualdades sociais e como inculcadoras dos valores e interesses das classes sociais que detêm o poder econômico e político. As práticas curriculares, avaliativas e de gestão das escolas brasileiras vêm, ao longo da história, corroborando um contexto de exclusão de um enorme contingente de brasileiros da plenitude de significado do direito à educação composto pelo acesso, pela permanência e pela qualidade para todos.

Primeiramente pela dificuldade de acesso, quando não havia acesso à educação obrigatória para a maioria dos brasileiros; depois, quando houve a ampliação do acesso por volta dos anos 1970, pelos mecanismos que levavam à reprovação de grande contingente de alunos que superavam a barreira do ingresso na etapa obrigatória de escolarização e; atualmente, com a quase universalização da oferta da etapa obrigatória de escolarização, o direito à educação vem sendo mitigado com a baixa qualidade do ensino oferecido pelas escolas, que faz com que muitos alunos percorram todas as séries do ensino fundamental, mas não se apropriem do instrumental mínimo para o exercício da cidadania num contexto em que o letramento é condição mínima para inserção social.

Se, no Brasil, não podemos falar de direitos como normas de civilidade nas relações sociais mediante os pressupostos da igualdade e da reciprocidade, podemos afirmar que esse ideal sempre esteve no horizonte político como campo de referência para as lutas pela cidadania.

Apesar de os direitos sociais terem sido inscritos no sistema normativo brasileiro desde a década de 1930, essa inscrição se deu desde uma perspectiva classista no contexto do Estado corporativo inaugurado por Getúlio Vargas. Disso resulta a íntima relação entre os direitos sociais e o mundo do trabalho regulado e a exclusão de amplos contingentes da população brasileira (empregadas domésticas e trabalhadores rurais, por exemplo) das garantias sociais.

E é justamente esse campo de referência do possível que nos coloca o problema complexo da relação entre o projeto brasileiro de modernização e os princípios da igualdade e da responsabilidade social como chaves de compreensão para a questão da cidadania no Brasil e, mais ainda, nos desafia a entender "se" e "como" circulam socialmente os direitos conquistados nos embates travados nesses campos nas últimas décadas, como é o caso das garantias constitucionais 
de 1988, ou mais especificamente, "se" e "como" o direito tem se configurado como mediação jurídica e política nas relações sociais.

De início, é preciso destacar que a expansão das oportunidades de escolarização no Brasil foi assinalada por uma ambiguidade fundamental: ao mesmo tempo em que havia um reconhecimento, no nível do discurso, da educação escolar como fator importante para o desenvolvimento econômico e social, ou seja, como projeto civilizador, o direito ao acesso e à permanência na escola elementar era negado tanto pelo sistema normativo, quanto pelos mecanismos de seleção intra e extraescolares.

É inegável que, pelo menos desde 1934, o sistema normativo brasileiro inscreveu a educação como direito e que os avanços dessa inscrição foram notáveis tanto em relação à forma quanto em relação ao conteúdo. Também é inegável que o Brasil acompanhou a tendência mundial pela demanda por educação a partir da década de 1940 com processo significativo de expansão das oportunidades de escolarização (HOBSBAWN, 1995).

Apesar disso, no sistema normativo brasileiro, o direito à educação correspondeu à obrigatoriedade escolar como imposição ao indivíduo ${ }^{3}$ e não como responsabilidade estatal. Mesmo, quando se tornou responsabilidade estatal não havia uma concepção universalista que lhe servisse de base. Só a partir de 1988, ao direito à educação por parte do indivíduo, correspondeu à obrigatoriedade de oferecer educação por parte do Estado e só muito recentemente o Brasil atingiu índices de escolarização obrigatória alcançados por muitos países europeus desde o início da segunda metade do século XX.

Assim, após mais de um século de história constitucional, é que o país terá, no nível dos valores proclamados, o direito à educação inscrita a partir de uma lógica mais universalista, fazendo frente ao longo trajeto de iniquidades e privilégios na oferta da instrução elementar. De 1824 até 1988, as inscrições do direito à educação nos textos constitucionais eram assinaladas por uma concepção de que o mínimo era o bastante.

Dessa forma, se o direito pode ser definido como tipificação e definição de responsabilidade, bem como por relações sociais pautadas pela igualdade e pela reciprocidade, na educação brasileira só houve ruptura na racionalidade jurídica a partir de 1988.

Apesar de essa ruptura na racionalidade jurídica constituir grande avanço no campo do direito à educação, o desafio que está colocado é a ruptura na

3 Desde 1940, de acordo com o Código Penal Brasileiro, pais e responsáveis que não enviam crianças à escola incorrem em crime de abandono intelectual, cuja pena varia de reclusão ao pagamento de multas. Já a obrigatoriedade de oferta de educação gratuita, só foi inscrita na Constituição Federal de 1988 que prevê responsabilização da autoridade competente pela não-oferta ou pela oferta irregular da etapa obrigatória de escolarização. 
racionalidade política da sociedade em geral e dos trabalhadores em educação, uma vez que até mesmo nas instituições de ensino a educação não se configurou como direito entendido como medida que opera a passagem para a igualdade no plano das relações sociais.

Com efeito, ao lado do tardio surgimento de uma concepção mais universalista do direito à educação nos textos constitucionais, a dinâmica de expansão da escolarização obrigatória foi refreada, até a década de 1960, por mecanismos de seleção nas instituições escolares. Mantínhamos uma escola "de" e "para" as elites que tinham objetivos convergentes com os da escola: buscava-se prestígio, inserção no mercado de trabalho e ascensão social. Dessa forma, o acesso à educação era fator de diferenciação social, pois mediante rigorosos mecanismos de seleção e ensino propedêutico voltado para o acesso a níveis superiores de educação ou para postos mais elevados no mercado de trabalho eram "eleitos" aqueles que seriam incluídos nos demais direitos de cidadania.

O crescimento da população urbana e a industrialização do país a partir da década de 1940 contribuíram para o aumento das pressões sociais por expansão das oportunidades de escolarização. Essas demandas por ampliação das oportunidades de escolarização, ainda que atendidas de forma precária nos marcos do populismo, interferiram na ação estatal no sentido da efetivação do princípio da igualdade de oportunidade para o acesso nas décadas seguintes.

Contudo, foi entre as décadas de 1970 e 1990 que houve um aumento expressivo no número de matrículas na etapa obrigatória de escolarização. Mas outras formas de exclusão assumiram a posição central no processo de escolarização nas décadas de 1970 e 1980: os próprios procedimentos internos da escola, sua estrutura e funcionamento, que conduziam à elitização do ensino, não mais por falta de vagas ou mecanismos de seleção, mas mediante a produção do fracasso escolar (repetência, evasão) como fator de diferenciação entre os merecedores e os não merecedores do acesso ao saber historicamente construído.

$\mathrm{Na}$ década de 1990 assistimos a um processo de expansão das oportunidades de escolarização, em que esses mecanismos internos de exclusão por parte da escola foram amenizados (democraticamente ou não) por políticas de regularização do fluxo (ciclos, progressão continuada, aceleração da aprendizagem). Porém, novamente, "estratégias" de exclusão foram criadas pela dinâmica interna da escola: os alunos percorrem todas as séries ou todos os ciclos do ensino fundamental sem se apropriar de um instrumental mínimo necessário para a inserção social.

Esses mecanismos internos de exclusão forjados no interior das práticas educativas precisam ser superados para a ruptura da racionalidade política dos trabalhadores em educação, uma vez que a defesa da educação como direito não significa a sua consolidação no campo das representações sociais. Do lado 
da sociedade, a ruptura da racionalidade política, deve passar, necessariamente, pela aceitação, circulação social e defesa nos fóruns apropriados dos mecanismos jurídicos que assegurem não só vagas, mas também qualidade de ensino nas escolas públicas, além da superação da resistência aos direitos assegurados no Estatuto da Criança e do Adolescente, tido, muitas vezes por professores e pais como um instrumento que elimina a autoridade paterna ou docente, ao proibir o trabalho infantil ou ao proteger o aluno das relações de poder estabelecidas na dinâmica interna das práticas escolares.

Se por um lado, hoje a educação é proclamada como direito do cidadão e dever do Estado e estamos, segundo o discurso oficial, muito próximos da universalização do acesso no ensino fundamental, por outro lado, as representações sociais estão muito distantes das promessas de emancipação e de igualdade que estão na base do direito à educação.

Dessa forma, a ruptura dessa racionalidade política excludente é o grande desafio histórico para esse século no que diz respeito à educação obrigatória e, se temos a definição jurídica da questão da responsabilidade social com a educação, ainda há um longo percurso quanto às representações sociais sobre os valores do direito, da igualdade e da inclusão.

\section{Conclusões}

Na epígrafe desse artigo utilizamos a música popular para inscrever a dívida histórica do país com a constituição de um sistema nacional de ensino e com a garantia do direito à educação: "Filho vir da escola problema maior é o de estudar, Que é pra não ter meu trabalho e vida de gente levar". Analisar o processo de constituição histórica das iniquidades quanto ao acesso, à permanência e à qualidade é uma importante tarefa para superação - no campo nas racionalidades políticas, das práticas cotidianas e das representações sociais - para colocarmos em relevo talvez o maior desafio da sociedade brasileira do século XXI: a universalização de uma educação com caráter público, republicano, democrático e igualitário. 
ARAUJO, G. C. Estado, política educacional e direito à educação no Brasil...

\section{REFERÊNCIAS}

BOTO, Carlota. A escola do homem novo: entre o Iluminismo e a Revolução Francesa. São Paulo: Unesp, 1996.

BOURDIEU, Pierre. Contrafogos: táticas para enfrentar a invasão neoliberal. Rio de Janeiro: Jorge Zahar, 1998.

ENGELS, Friedrich. A origem da família, da propriedade privada e do Estado. 3. ed. São Paulo: Global, 1986.

HOBSBAWM, Eric. A era dos extremos: o breve século XX: 1914-1991. São Paulo: Companhia das Letras, 1995.

HORTA, José Silvério Baia. Direito à educação e obrigatoriedade escolar. Cadernos de Pesquisa da Fundação Carlos Chagas, São Paulo, n. 104, p. 5-34, 1998.

SACRISTÁN, Jose Gimeno. A educação obrigatória: seu sentido educativo e social. Porto Alegre: ARTMED, 2000.

SMITH, Adam. A Riqueza das Nações. São Paulo: Abril Cultural, 1983.

TELLES, Vera da Silva. Direitos Sociais: afinal do que se trata? Belo Horizonte: UFMG,1999.

WEBER, Max. Economia e Sociedade. Brasília: UnB/Senado Federal, 2004. v. 2.

Texto recebido em 24 de outubro de 2009

Texto aprovado em 04 de novembro de 2009 